\title{
Serological Relationships and Some Properties of Tobacco Necrosis Virus Strains
}

\author{
By P. BABOS AND B. KASSANIS \\ Rothamsted Experimental Station, Harpenden, Hertfordshire
}

(Received 28 December 1962)

\section{SUMMARY}

Isolates from seven virus stocks called tobacco necrosis were serologically related, but fell into two groups (serotypes) showing widely different degrees of serological relationship. Serotype A contained the five closely related strains $\mathrm{A}, \mathrm{B}, \mathrm{C}$ (Dutch cucumber necrosis virus), $\mathrm{F}$ and $\mathrm{s}$ (bean stipple-streak virus); and serotype D strains $\mathrm{D}$ and $\mathrm{E}$. Strains $\mathrm{A}$ and $\mathrm{F}$, isolated in Britain and the U.S.A. respectively, are possibly identical, but the others could be distinguished by the kinds of lesions caused in French bean, and $\mathrm{c}$ by the symptoms it causes in young cucumber plants. The virus particles of all strains were hexagonal in outline and of the same width. They had the same absorption spectrum and sedimentation constants, and all except strain B crystallized into rhombic plates. Only strain D failed to aid the multiplication of the satellite virus. It is proposed to restrict the name tobacco necrosis to viruses serologicaly related to what seems the commonest strain, namely, A.

\section{INTRODUCTION}

Tobacco necrosis was the name given by Smith \& Bald (1935) to a virus disease of tobacco seedlings in which the lower leaves developed necrotic streaks along the midrib, while the upper ones remained symptomless and virus-free. The roots of infected plants contained virus as also did the roots of many healthylooking plants. Bawden (1941) found that the symptoms of tobacco necrosis could be caused by serologically unrelated viruses and Bawden \& Pirie (1942, 1945) described the purification and properties of strains of these viruses. They did not propose any new names for the serologically unrelated viruses, but distinguished different virus cultures by the place or host from which they came. All the cultures caused necrotic local lesions only in tobacco, French bean and all other hosts to which they were inoculated, but since then three viruses have been described under the name tobacco necrosis that caused systemic diseases, namely stipple-streak of bean (Bawden \& Van der Want, 1949), Augusta disease of tulip (Kassanis, 1949) and cucumber necrosis (Van Koot \& Van Dorst, 1955; McKeen, 1959). Our work was done to compare the properties and to find the serological relationship between a range of these viruses.

\section{METHODS}

Tobacco necrosis viruses were derived from several sources and will be specified with a small capital letter for the sake of brevity. They will thus be referred to as e.g., TNVA or strain A. Strain A was isolated from a naturally infected tobacco root (Kassanis, 1960; Kassanis \& Nixon, 1961). Strain B is the major infective component 
of the Rothamsted TNv culture (Bawden \& Pirie, 1942; Kassanis \& Nixon, 1961). Strain D came from the leaves of a normal looking Datura tatula plant. Strain $\mathrm{s}$ is from the stock culture of bean stipple-streak virus, supplied by Dr D. Noordam. Strain $\mathrm{C}$ is an isolate of cucumber necrosis virus from Holland supplied by Dr Van Dorst. Strains E and F came from cultures of TNv supplied to us by Dr D. Teakle from U.S.A. Satellite virus was obtained as before (Kassanis, 1962). Each strain was derived from a single lesion after a series of single-lesion isolations. The serial transfers from single lesions were usually done on French bean (Phaseolus vulgaris L., var. Prince) but occasionally on Nicotiana tabacum L., var. Xanthi. Strain s was isolated from the young leaves of a succession of systemically infected French beans before it was inoculated to tobacco in which several serial singlelesion transfers were made and each one was tested in French bean to ensure that it became systemic. After the last transfer, inoculum from a single lesion was rubbed over as many bean leaves as possible, and these leaves supplied the inoculum for inoculating a large number of tobacco plants. The tobacco sap was stored as $2 \mathrm{ml}$. samples at $-20^{\circ}$ and used throughout the entire work. These precautions were taken to ensure the purity of the strains because leaves of apparently healthy plants often contain TNV (Kassanis \& Nixon, 1961; Babos \& Kassanis, 1963b).

The viruses were purified as before (Kassanis \& Nixon, 1961), except that they were salted out with ammonium sulphate at $30 \%$ saturation before the two cycles of high and low-speed centrifugation. The precipitation with ammonium sulphate was omitted when strain B was purified as it denatured much of the virus. The virus preparations in water were kept at $4^{\circ}$. The purified preparations of all strains were colourless except those of strain B which were light brown. Concentrations were estimated by optical density at $260 \mathrm{~m} \mu$ using a Unicam SP 500 spectrophotometer.

For infectivity tests the primary leaves of French bean were inoculated when not quite fully expanded and before any trifoliate leaves had expanded. All experimental plants were kept in an insect-proof glasshouse at an average temperature of $20^{\circ}$. Inoculations were made by rubbing the upper surfaces of leaves with the forefinger wet with inoculum. To increase the number of lesions, 'Celite' (a diatomaceous earth) was mixed with the inoculum.

Antisera were prepared by injecting rabbits intravenously with two doses of $3 \mathrm{mg}$. of purified virus, at an interval of a week. The rabbits were bled 10 days after the second injection. The antisera were stored at $4^{\circ}$ with $0.5 \%$ phenol added. Six antisera were prepared, two against strain $D$ and one each against $\mathbf{A}, \mathbf{B}, \mathrm{F}$ and $\mathrm{s}$ strains. None reacted with sap from uninfected plants.

Serological tests were made either by precipitation tests in narrow tubes or by double gel-diffusion precipitation in $\mathbf{0 . 5} \%$ 'Ionagar' (or purified Difco-Bacto agar) dissolved in different buffers. Reservoirs were cut with a cork borer $0 \cdot 6 \mathrm{~cm}$. diameter and the distance between reservoirs was usually $0 \cdot 2 \mathrm{~cm}$.

Sedimentation constants were determined with a Spinco Model E ultracentrifuge.

Mr R. D. Woods did the electron microscopy on purified virus preparations by methods previously described (Kassanis \& Nixon, 1961). 


\section{RESULTS}

\section{Symptoms in French beans}

Of a range of commonly grown experimental plants tested to find a differential host for the strains, French bean was the best. Except strain s, which caused no obvious local lesions and became systemic, all strains caused only necrotic local lesions, but these differed enough in colour and size, and in the time they took to become visible, to permit reliable identification. The small, round, dark reddish brown necrotic local lesions produced by strain A within 2 days of inoculation gradually spread along the veins giving a network of red-brown necrotic tissue with almost transparent interveinal areas. They increased in size with time and, when few, reached $4 \mathrm{~cm}$. in diameter before the leaf abscissed. The lesions produced by strain B took about 3 days to appear. They were dull red-brown and spread along the veins like those caused by strain $A$, the interveinal areas becoming transparent. They, too, increased in size until the leaf abscissed (Pl. 1, fig. 1). Strains C and F produced lesions similar to those caused by $\mathrm{A}$, but $\mathrm{c}$ could be distinguished by the systemic infection caused in very young cucumber plants.

Strain D was isolated from the leaves of a normal-looking Datura tatula L. plant. When it was first inoculated on to French bean minute necrotic lesions appeared 3 days after inoculation, and remained small. Transfers from these lesions to further beans gave lesions of different sizes and some increased in size considerably in one direction only (Pl. 1, fig. 4). Inoculation to bean from any part of such an outgrown lesion gave only one kind of lesion. The minute lesions appeared several times during our work and their formation seemed dependent on the physiological condition of the bean plants. Inoculations from the same purified preparation often gave large lesions in one plant and small in another growing in the same pot, but occasionally the two kinds of lesion appeared on the same leaf. This strain differs from the rest in that its lesions remained discrete and did not spread along the veins. The reddish brown lesions, which almost always remained circular in outline, grew to about $1 \mathrm{~cm}$. in diameter after about 2 weeks and then seemed to consist of concentric rings (Pl. 1, fig. 3).

Strain $\mathrm{E}$ formed lesions intermediate between those formed by strains $\mathrm{A}$ and $\mathrm{D}$. Two days after inoculation they appeared as distinct dark reddish brown spots which became irregular in outline and eventually reached the smallest adjacent veins. They continued to increase, but did not spread along the larger veins like those caused by strain A or B (Pl. 1, fig. 2).

The culture of bean stipple-streak virus supplied by Dr D. Noordam produced only necrotic local lesions in French bean during the winter, but when temperature increased a few plants became systemically infected. The rarity of systemic infections was found to be because the culture contained satellite virus which interfered with the multiplication of the stipple-streak virus. Strain s isolated from this culture, and freed from the satellite virus, infected French bean systemically throughout the year, although the severity and kind of symptoms varied with the season. During spring and winter the symptoms were very severe; the inoculated leaves showed veinal necrosis with occasional interveinal green or yellow mottling. The mottled leaves became stiff and brittle with their edges often curled downwards. Long streaks formed on the petioles and often on the stems. The necrosis extended 
to the growing point and to the young trifoliate leaves, killing the whole plant. During summer the leaves were severely mottled but less necrotic, shoots proliferated extensively and some plants fruited although both their flowers and pods showed lesions (Pl. 1, fig. 5). The virus concentration was high in all infected tissues.

\section{Serological relationships}

Tube precipitation tests. The six antisera were titrated against six of the isolates, using the virus at no more than $0.02 \mathrm{mg} . / \mathrm{ml}$. to avoid antigen excess at the higher dilutions of antiserum. All six viruses were serologically related but the antiserum titres against the heterologous viruses showed that the six fell into two groups (Table 1). Cross-absorption tests showed that strains within each group also differed serologically from each other, although to a lesser extent than between groups.

Table 1. The reciprocals of precipitation titres of tobacco necrosis virus antisera against homologous and heterologous antigens

$\begin{gathered}\text { Test } \\ \text { antigen }\end{gathered}$
A
F
S
B
D
E

\begin{tabular}{|c|c|c|c|c|c|}
\hline \multicolumn{6}{|c|}{ Antiserum } \\
\hline A & $\mathbf{F}$ & $\mathbf{S}$ & $\mathbf{B}$ & D1 & D2 \\
\hline 1024 & 4096 & 4096 & 256 & 32 & 32 \\
\hline 1024 & 4096 & 4096 & 256 & 32 & 32 \\
\hline 1024 & 4096 & 4096 & 256 & 4 & 32 \\
\hline 1024 & 4096 & 4096 & 256 & 4 & 32 \\
\hline 32 & 256 & 256 & 8 & 256 & 512 \\
\hline 32 & 256 & 256 & 8 & 128 & 256 \\
\hline
\end{tabular}

A series of two-fold dilutions of antiserum were incubated with equal volume of $0.02 \mathrm{mg} . / \mathrm{ml}$. of purified virus. The titres were recorded after standing for $5 \mathrm{hr}$. at $37^{\circ}$ and overnight at room temperature.

For absorption the mixture of antiserum and heterologous virus at optimal proportions was incubated for $5 \mathrm{hr}$. at $37^{\circ}$ and then kept overnight at $4^{\circ}$ before the resulting precipitate was removed by low-speed centrifugation. When the absorbed antisera were titrated, the unabsorbed were also tested as controls. Antisera to strains $A, B, S$ and $D$ were absorbed with some of the strains selected to provide the maximum information on antigenic composition. Each absorbed antiserum was tested against all strains except C. Antisera against strains A, B, F and s had few antibodies reacting with strains $\mathrm{D}$ or $\mathrm{E}$, and vice versa. After an antiserum was absorbed with a strain belonging to the other group, its titre against the homologous antigen was unchanged. Using the nomenclature proposed by Kassanis (1961) the viruses in the two groups are serotypes, and those within each group strains of one another.

When an antiserum was absorbed by a member of the same group most or all antibodies were removed. Such tests showed that strains $A$ and $F$ were indistinguishable in antigenic composition, and their similarities in other properties imply that they may well be identical. The inability of any other strain to absorb completely the antibodies in antisera prepared against strains $\mathrm{A}, \mathrm{B}$ or $\mathrm{D}$ indicates that they have specific antigenic determinants. Absorption of antiserum to strain $\mathrm{s}$ with strain $\mathrm{B}$ showed an antigen common to strains $\mathrm{A}, \mathrm{F}$ and $\mathrm{s}$, which was not found in strain $\mathrm{B}$, whereas absorption of antiserum to strain $B$ with strain $s$ showed an antigen common to $A, F$ and $B$, which was not possessed by strain $\mathbf{s}$. 
The two antisera prepared against strain $\mathrm{D}$ differed in antibody composition. All cross-reacting antibodies were removed from both antisera when absorbed by strain E. Antiserum D 1 contained some antibodies that reacted only with strains A and $F$ of the other group, as indicated by absorption with strain B or $\mathrm{S}$, whereas antiserum D2 still reacted with strain B after absorption with strain A or s (Table 2). From these results the minimum antigenic composition of each strain can be derived. Strains $A$ and $F$ appeared identical, and more closely related to strains $B$ and $\mathrm{S}$ than strain B to strain S. Strains A and B are equally related to strains $D$ and $E$, but strain $\mathrm{S}$ is less so. The close relationship between strains $\mathrm{D}$ and $\mathrm{E}$ indicates that these two strains form a separate serotype with a large proportion of specific antigenic determinants.

Table 2. The reciprocals of precipitation titres of absorbed antisera to strains of tobacco necrosis virus

\begin{tabular}{|c|c|c|c|c|c|c|c|}
\hline \multirow[b]{2}{*}{ Antiserum } & \multirow{2}{*}{$\begin{array}{c}\text { Antigen } \\
\text { used for } \\
\text { absorp- } \\
\text { tion }\end{array}$} & \multicolumn{6}{|c|}{ Antigen used for testing } \\
\hline & & $\mathbf{A}$ & $\mathbf{F}$ & $\mathrm{s}$ & B & D & $\mathbf{E}$ \\
\hline A & $\begin{array}{l}\mathbf{s} \\
\mathbf{D}\end{array}$ & $\begin{array}{c}8^{*} \\
1024\end{array}$ & 8 & $\begin{array}{r}0 \\
1024\end{array}$ & $\begin{array}{r}0 \\
1024\end{array}$ & $\begin{array}{l}0 \\
0\end{array}$ & \\
\hline $\mathbf{S}$ & $\begin{array}{l}\text { A } \\
\text { B } \\
\text { D }\end{array}$ & $\begin{array}{r}0 \\
16 \\
4098\end{array}$ & $\begin{array}{r}0 \\
16 \\
4096\end{array}$ & $\begin{array}{r}0 \\
16 \\
4096\end{array}$ & $\begin{array}{r}0 \\
0 \\
4096\end{array}$ & $\begin{array}{l}0 \\
0 \\
0\end{array}$ & \\
\hline B & $\begin{array}{l}\text { A } \\
\text { s } \\
\text { D }\end{array}$ & $\begin{array}{r}0 \\
16 \\
256\end{array}$ & $\begin{array}{r}0 \\
16 \\
256\end{array}$ & $\begin{array}{r}0 \\
0 \\
256\end{array}$ & $\begin{array}{r}4 \\
16 \\
256\end{array}$ & $\begin{array}{l}0 \\
0 \\
0\end{array}$ & \\
\hline D1 & $\begin{array}{l}\text { A } \\
\text { B } \\
\text { S } \\
\text { E }\end{array}$ & $\begin{array}{r}0 \\
16 \\
16 \\
0\end{array}$ & $\begin{array}{r}0 \\
16 \\
16 \\
0\end{array}$ & $\begin{array}{l}0 \\
0 \\
0 \\
0\end{array}$ & $\begin{array}{l}0 \\
0 \\
0 \\
0\end{array}$ & $\begin{array}{r}\mathbf{2 5 6} \\
\mathbf{2 5 6} \\
\mathbf{2 5 6} \\
\mathbf{3 2}\end{array}$ & $\begin{array}{r}128 \\
128 \\
128 \\
0\end{array}$ \\
\hline D2 & $\begin{array}{l}\mathbf{A} \\
\mathbf{S} \\
\mathbf{B} \\
\mathbf{E}\end{array}$ & $\begin{array}{l}0 \\
8 \\
0 \\
0\end{array}$ & $\begin{array}{l}0 \\
8 \\
0 \\
0\end{array}$ & $\begin{array}{l}0 \\
0 \\
0 \\
0\end{array}$ & $\begin{array}{r}16 \\
32 \\
0 \\
0\end{array}$ & $\begin{array}{r}512 \\
512 \\
512 \\
64\end{array}$ & $\begin{array}{l}\mathbf{2 5 6} \\
\mathbf{2 5 6} \\
\mathbf{2 5 6}\end{array}$ \\
\hline
\end{tabular}

* The figures are reciprocals of precipitation titres of absorbed antisera. The sign 0 signifies absence of precipitation at the lowest dilutions tested, which were $1 / 8,1 / 8,1 / 2,1 / 4$, and $1 / 2$ for antisera against strains $\mathrm{A}, \mathrm{S}, \mathrm{B}, \mathrm{Dl}$ and $\mathrm{D} 2$ respectively. Titres of unabsorbed antisera are shown in Table 1.

In addition to the cucumber necrosis virus found in Holland by Van Koot $\&$ Van Dorst (1955) and designated here as strain c, there is the Canadian cucumber necrosis virus which McKeen (1959) showed to be serologically unrelated to tobacco necrosis virus but included in the tobacco necrosis group because of certain similarities. Using an inoculum provided by Dr McKeen, we found this virus unrelated serologically to either of our serotypes and the lesions produced in French beans distinctly differed from any described here.

Diffusion precipitation tests in agar-gel. Titration of TNV antiserum in agar-gel against homologous or heterologous antigen showed that at several antigenantibody $(\mathrm{Ag} / \mathrm{Ab})$ ratios, irrespective of buffer, $\mathrm{pH}$ and ionic concentration, two and sometimes three, precipitation lines were formed, especially when the distance between reservoirs was $0.9 \mathrm{~cm}$. When the distance was $0.2 \mathrm{~cm}$., often there was only 
one line that split at either end, probably because at these points the reactants travelled longer distances to meet at optimal proportions. The phenomenon was not caused by contamination of the antigen and antiserum with a different strain, because such large contamination as indicated by the intensity of the lines could easily have been detected by infectivity tests. Neither sap from healthy plants, nor the material produced by subjecting large quantities of such sap to TNV precipitation procedure, reacted with any antiserum either in gel-diffusion tests or in tube precipitation tests. The double line might have been caused by the breakage of the virus into fragments whose size, antigenic composition and diffusion coefficient determined the position of the precipitation line. This is suggested by the fact that sometimes the two lines crossed each other. These fragments must have similar electrophoretic mobilities in agar because they were not separated by immunoelectrophoresis. Two or more lines in an appärently homogeneous antigen reacting with its homologous antiserum have been reported with other antigens and these are discussed by Crowle (1960).

All strains, except strain B, produced clearly visible precipitation lines with their homologous or heterologous antisera in different buffers and $\mathrm{Ag} / \mathrm{Ab}$ ratios. Of the several buffers in which agar was dissolved (tris, phosphate, borate, and veronal) borate gave the best line definition and sensitivity at $\mathrm{pH} 7$ to 8.3 at wide $\mathrm{Ag} / \mathrm{Ab}$ ratios. Line formation with strain $B$ against any antiserum was erratic and often no line formed irrespective of the conditions of the test. This strain also differed from the rest in flattening when air-dried on collodion film and breaking into fragments when stained with sodium phosphotungstate for electron microscopy. Incubation with an equal volume of $2 \%$ formaldehyde for $\mathbf{3 0}$ min. stabilized the particles (Kassanis \& Nixon, 1961). This treatment also allowed strain B to form precipitation lines in any medium with any of the antisera tested. All experiments involving this strain were therefore done with formaldehyde-treated material. Precipitation in gel was much less sensitive than precipitation in tubes. The minimum concentration of virus that produced a line with homologous antiserum at dilutions $1 / 5$ to $1 / 20$ was between 0.05 and $0.1 \mathrm{mg} . / \mathrm{ml}$, as against $0.004 \mathrm{mg} . / \mathrm{ml}$. in the tube precipitation test.

To investigate relationship between strains, a single undiluted antiserum was placed in the central reservoir and the strains at appropriate concentrations were arranged in all possible combinations in the surrounding reservoirs. The antigenic relationships between the strains suggested by this method were the same as that given by the tube precipitation method. Spurs were formed by those strains which had an antigen not shared by the strain in the neighbouring reservoir. The spurs were deflected from the parent line when strains in each serotype were compared, and continued the course of the parent line without deflection when strains from the two serotypes were compared. When strains from the two serotypes were compared in neighbouring reservoirs against the mixed antiserum of the two, the lines crossed apparently without deflection. It is therefore worth noting that the crossing of the lines of two antigens tested against mixed antiserum does not necessarily signify complete lack of relationship.

Similar results were obtained in immunoelectrophoretic tests using the technique described by Hirschfeld (1960). As the strains had different electrophoretic mobilities in agar-gel crosses or spurs were easily formed when a mixture of two strains 
was run and tested against antiserum. This method confirmed the findings of the double diffusion method and also checked the purity of the preparations. When virus preparations of strain A were run at $6 \mathrm{mg} . / \mathrm{ml}$. and tested against an antiserum to strain D a single line was produced. This test had a sensitivity of about $0.025 \mathrm{mg} . /$ ml. All strains, except $\mathrm{B}$, moved towards the negative pole at speeds depending on the buffer used. Under the same conditions strain B was either stationary or moved towards the positive pole. As strain $\mathrm{B}$ has greater electrophoretic mobility in liquid medium than the other strains, the immunoelectrophoretic results indicate that the effect of electroosmosis was greater than that of electrophoresis.

\section{Some properties}

Crystallization. When concentrated virus solutions were sedimented in the ultracentrifuge the pellets of strains $\mathrm{A}, \mathrm{F}$ and s sometimes became insoluble in water; suspensions of the pellets showed a strong sheen and consisted of numerous small flat rhombic crystals of various thicknesses (Pl. 1, fig. 6), which usually dissolved overnight at $4^{\circ}$. With some preparations, however, not all the crystals dissolved; these were centrifuged at low speed and dissolved in $0.067 \mathrm{M}$-phosphate buffer $\mathrm{pH} 7$.

Virus preparations in distilled water left at $4^{\circ}$ for several months sometimes crystallized, especially strains $A, F$ and $D$, but never preparations of strain $B$. All strains, except B, were easily crystallized by adding saturated ammonium sulphate solution drop-wise until a slight turbidity appeared. The solution was then left at $4^{\circ}$ overnight or longer for the crystals to separate. These crystals were also rhombic plates of variable thickness; the small angle made by the sides of the plates was $79^{\circ}$, as recorded by Bawden \& Pirie (1942) for a strain found in the roots of a potato plant which was called potato culture (Pl. 1, fig. 7).

Electron microscopy. Kassanis \& Nixon (1961) reported that particles of strain A had a diameter about $5 \mathrm{~m} \mu$ larger than strain в when shadowed or negatively stained with sodium phosphotungstate. We found no significant difference in size between any of the strains, including $\mathrm{A}$ and в. The negatively stained particles were hexagonal in outline and their diameter ranged from 25.9 to $26.7 \mathrm{~m} \mu$. A second examination of strain $\mathrm{A}$ by the same methods gave a diameter of $30 \mathrm{~m} \mu$. The condition of the virus or the way the specimens are prepared for electron microscopy may influence the apparent size of the particles. Whatever the real size may be, it seems unlikely that there is any consistent difference in size between strains. Strain B was fixed with an equal volume of $2 \%$ formalin before staining, to preserve the integrity of the particles (Kassanis \& Nixon, 1961). There was no evidence that formalin fixing alters the size of the particles; strain $\mathrm{s}$ had the same diameter fixed or unfixed.

Ultraviolet light absorption. The u.v. absorption spectrum of all strains was the same, with a maximum at $260-262 \mathrm{~m} \mu$ and a minimum at 242-244 $\mathrm{m} \mu$. The ratio of maximum to minimum differed between preparations from 1.2 to 1.7 , the most frequent being $1 \cdot 3$, irrespective of strain used. The ratio of absorbancies at 260 and $280 \mathrm{~m} \mu$ was 1.5 .

The virus concentrations of several purified preparations were found by estimating dry weight or total nitrogen, from which the specific extinction coefficient at $260 \mathrm{~m} \mu$ was determined. The values were somewhat variable, but no systematic deviation 
from the mean was observed for any strain. The average extinction coefficient was 5.5 per $\mathrm{mg} . / \mathrm{ml}$. Phenol-extracted nucleic acid in $0.067 \mathrm{M}$-phosphate buffer, $\mathrm{pH} 7$ gave a maximum at $260 \mathrm{~m} \mu$ and a minimum at $240 \mathrm{~m} \mu$. The maximum to minimum ratio ranged from $1 \cdot 7$ to $2 \cdot 4$ and the $260 / 280$ ratio was $1 \cdot 5$.

Sedimentation. Sedimentation constants for several TNV isolates have been reported (Pirie, Smith, Spooner \& McClement, 1938; Price \& Wyckoff, 1939; Bawden \& Pirie, 1942; Kassanis \& Nixon, 1961). The values obtained ranged between $112 S$ and $130 S$. Strains $\mathrm{D}, \mathrm{E}$ and $\mathrm{s}$, never previously examined, were centrifuged at two concentrations in distilled water. The sedimentation constants obtained were between 116 and $120 \mathrm{~S}$.

\section{Interactions with satellite virus}

Satellite virus multiplies in the presence of $\mathrm{TNV}_{\mathrm{N}}$ strains $\mathrm{A}$ and $\mathrm{B}$, but not in mixed infections with several other viruses (Kassanis \& Nixon, 1961; Kassanis, 1962). The concentration of satellite virus in the presence of all strains was compared in tests using French bean leaves as the host. The inoculated leaves were usually detached and placed on a wet towel in trays covered with polythene sheet, as this gave greater virus concentrations, especially with strain $\mathrm{D}$. Five days after inoculation, the sap was extracted and the individual virus content estimated serologically. Satellite virus is not serologically related to either of the two TNV serotypes.

Table 3. The concentration of tobacco necrosis virus $(T N V)$ and satellite virus in French beans in single and double infections determined by serological precipitation tests

$\begin{array}{ccccc}\text { Strains } & \overbrace{\begin{array}{c}\text { Homologous } \\ \text { antiserum }\end{array}}^{\text {TNV alone }} & \begin{array}{c}\text { Antiserum to } \\ \text { satellite virus }\end{array} & \overbrace{\begin{array}{c}\text { Homologous } \\ \text { antiserum }\end{array}}^{\text {TNV + satellite virus }} \\ \text { A } & 32^{*} & 0 & 4 & \begin{array}{c}\text { Antiserum to } \\ \text { satellite virus }\end{array} \\ \text { B } & 8 & 0 & 8 & 16 \\ \text { S } & 64 & 0 & 8 & 128 \\ \text { D } & 16 & 0 & 16 & 32 \\ \text { E } & 8 & 0 & 4 & 0\end{array}$

* Reciprocals of virus dilution end points in precipitation tests determined by incubating serial two-fold dilutions of heat-clarified sap with the indicated antiserum diluted 1/50. Strains $F$ and $\mathrm{c}$ behaved as strain $\mathrm{A}$. The satellite virus did not multiply when inoculated alone.

Only strain D failed to induce the multiplication of satellite virus (Table 3). In this and other experiments, strains $\mathrm{B}$ and $\mathrm{s}$ were usually more effective than strains A, F and C. All these strains have major antigens in common. Strain E, although not closely related to the other strains, also assisted the multiplication of the satellite virus, but usually less than the others. Satellite virus multiplied at the expense of the assisting viruses, decreasing their lesion-size as well as their concentration. At certain ratios of the concentration of the satellite and assisting viruses the lesion number is also decreased (Kassanis, 1962) (Pl. 1, fig. 2). The ability of these strains to induce the multiplication of satellite virus is not related to their antigenic composition. 


\section{DISCUSSION}

All the TNv isolates we have studied were serologically related. They fall into two groups, or serotypes, each containing distinguishable strains. Serotype A contains strains $\mathrm{A}, \mathrm{B}, \mathrm{C}, \mathrm{F}$ and $\mathrm{s}$; and serotype $\mathrm{D}$ strains $\mathrm{D}$ and $\mathrm{E}$. No serological differences were detected between $\mathrm{A}, \mathrm{F}$ and $\mathrm{c}$, but the last could be distinguished because it became systemic in young cucumber plants. Apart from the serological differences, the strains can be identified by the symptoms they cause on French bean and by some other properties, e.g. strain в fails to crystallize, loses its infectivity faster than the others and breaks up when stained with sodium phosphotungstate, unless fixed with formalin. The thermal inactivation rates and rates at which they multiply in the plants are also useful in distinguishing between the different strains (Babos \& Kassanis, 1963 $a, b$ ).

Our strains do not include all the kinds of tobacco necrosis viruses described by Bawden \& Pirie (1942), for we have found only one crystal type and they reported several. The crystals formed by six of our strains resemble those of the potato culture, which they found to be serologically related to some that crystallized in different ways. From an old preparation of the potato culture given to us by $\mathrm{Mr}$ N. W. Pirie we obtained a virus that in every way resembles our strain A. The cultures called Princeton, Potato and Tobacco VI by Bawden \& Pirie therefore are probably closely related serologically to our strain A. Of the cultures they reported as serologically unrelated to the potato culture, Tobacco I and II no longer exist and we have encountered nothing like them. Hence they may well be quite unrelated to any of our strains. The Rothamsted culture has been maintained continuously since 1942 and from it Kassanis \& Nixon (1961) isolated both the strain called $\mathrm{B}$ and the satellite virus. Some of the properties Bawden \& Pirie (1942) reported for the infective component of the Rothamsted culture suggest that it was strain $\mathrm{B}$, even though they reported it to be serologically unrelated to the potato culture, which we find is serologically related to strain B. One likely reason for the discrepancy is that the purified preparations of the Rothamsted culture Bawden and Pirie used as antigen had been treated in ways that largely inactivated strain B and they possibly contained only the satellite virus which is antigenically distinct from strain $\mathrm{A}$.

The name tobacco necrosis virus is now largely meaningless, for it is used, not only for viruses that cause the disease first given this name, but also for viruses that cause systemic diseases. We propose that it should now be restricted and defined in terms of serological relationships. There is reason to think that the original cultures used by Smith \& Bald (1935) and most of those studied by Bawden \& Pirie (1942) contained viruses serologically related to those we have studied and we suggest that the name should now be used only for viruses serologically related to them. This means excluding the viruses called Tobacco I and II by Bawden \& Pirie (1942), should they be rediscovered. The virus causing cucumber necrosis in Canada (McKeen, 1959), which is not serologically related to our types, would also be excluded but the one that causes cucumber necrosis in Holland would be included in the group. 


\section{REFERENCES}

Babos, P. \& KaSSANis, B. (1963a). Thermal inactivation of tobacco necrosis virus. Virology (in the Press).

Babos, P. \& Kassanis, B. (1963b). The behaviour of some tobacco necrosis virus strains in plants. Virology (in the Press).

BAwDEN, F.C. (1941). The serological reactions of viruses causing tobacco necrosis. Brit. J. exp. Path. 22, 59.

Bawden, F. C. \& Pirie, N. W. (1942). A preliminary description of preparations of some of the viruses causing tobacco necrosis. Brit. J. exp. Path. 23, 314.

Bawden, F. C. \& Pirie, N. W. (1945). Further studies on the purification and properties of a virus causing tobacco necrosis. Brit. J. exp. Path. 26, 277.

Bawden, F. C. \& van der WANT, J. P. H. (1949). Bean stipple-streak caused by tobacco necrosis virus. Tijdschr. PlZielkt. 55, 142.

Crowle, A. J. (1960). Interpretation of immunodiffusion tests. Annu. Rev. Microbiol. 14, 161.

HirschFEld, J. (1960). Immunoelectrophoresis-procedure and application to the study of group-specific variations in sera. Science Tools, 7, 18.

Kassanis, B. (1949). A necrotic disease of forced tulips caused by tobacco necrosis virus. Ann. appl. Biol. 36, 14.

Kassanis, B. (1960). Comparison of the early stages of infection by intact and phenoldisrupted tobacco necrosis virus. Virology, 10, 353.

Kassanis, B. (1961). Potato paracrinkle virus. Eur. Potato J. 4, 13.

Kassanis, B. (1962). Properties and behaviour of a virus depending for its multiplication on another. J. gen. Microbiol. 27, 477.

Kassanis, B. \& Nixon, H. L. (1961). Activation of one tobacco necrosis by another. $J$. gen. Microbiol. 25, 459.

MCKeEn, C. D. (1959). Cucumber necrosis virus. Can. J. Bot. 37, 913.

Pirie, N. W., Smith, K. M., Spooner, E. T. C. \& McClement, W. D. (1938). Purified preparations of tobacco necrosis virus. Parasitology, 30, 543.

Price, W. C. \& Wyckoff, R. W. G. (1939). Ultracentrifugation of juices from plants affected by tobacco necrosis. Phytopathology, 29, 83.

Sмith, K. M. \& BaLd, J. G. (1935). A description of a necrotic virus disease affecting tobacco and other plants. Parasitology, 27, 231.

van KoOt, Y. \& van Dorst, J. H. M. (1955). A new virus disease of cucumbers. Tijdschr. PlZiekt. 61, 163.

\section{EXPLANATION OF PLATE}

Fig. 1. French bean leaf inoculated with strain A (right half-leaf) and strain B (left half-leaf), three days after inoculation.

Fig. 2. French bean leaf inoculated with strain $\mathrm{E}$ (left half-leaf) and strain $\mathrm{E}$ with satellite virus (right half-leaf), 5 days after inoculation. Fewer and smaller lesions were caused by the mixed inoculum although the two halves were inoculated with the same concentration of strain $E$.

Fig. 3. French bean leaf inoculated with strain $\mathrm{D}, 2$ weeks after inoculation.

Fig. 4. Half French bean leaf showing atypical lesions of strain $D, 3$ weeks after inoculation.

Fig. 5. French bean plant systemically infected with strain $s$ (stipple-streak), 3 weeks after inoculating the primary leaves.

Fig. 6. A carbon replica of a small crystal of strain $\mathrm{A}$ formed during ultracentrifugation. $\times 36,000$ approx.

Fig. 7. Crystals of strain $\mathrm{A}$ formed in the presence of ammonium sulphate. $\times 150$. 

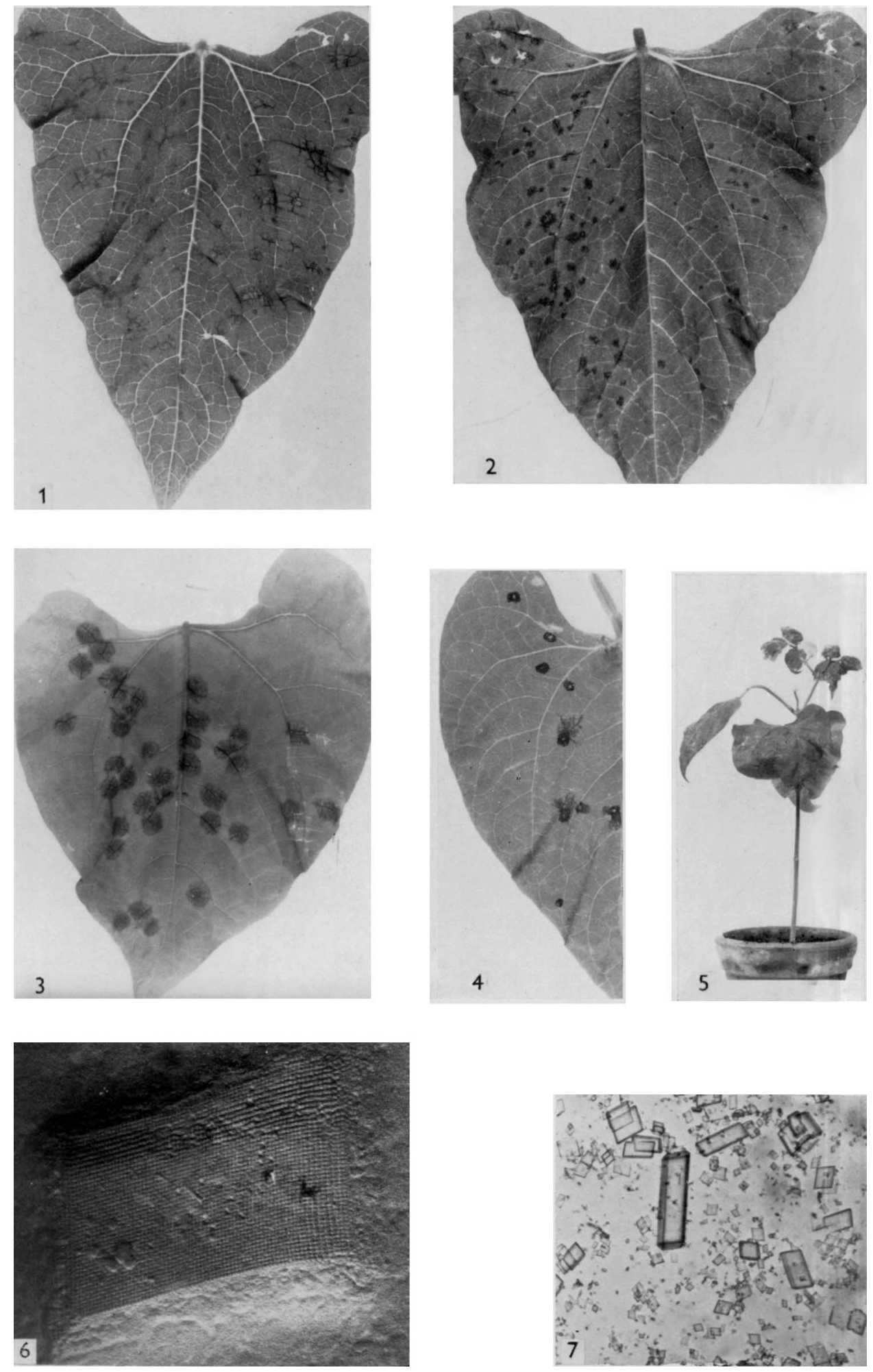

P. BABOS AND B. KASSANIS 